\title{
Cultivating Disciplinary Expectations for Engineering Education Research in Canada
}

\author{
Lydia E Carol-Ann Burke 1 - Alan Chong • \\ Greg J. Evans $\mathbb{D} \cdot$ Lisa Romkey
}

Published online: 3 March 2020

(C) Ontario Institute for Studies in Education (OISE) 2020

\begin{abstract}
Engineering education research in Canada is, in many ways, still establishing itself as a discipline, yet much is already being asked of it. The diversity of career pathways for engineering graduates, along with the increased complexity of global engineering challenges and the ramifications of technological opportunities, is raising important questions about current engineering education foci and practices. This paper brings together issues surfaced through the process of compiling a Special Theme on engineering education research in Canada, positioning the collection of papers in terms of the challenges and opportunities faced by this maturing Canadian research community. We seek to reconcile how this research can incorporate the theoretical and methodological depth valued in the social sciences while honoring the focus on effective instructional practices that has become an important strand of inquiry in engineering education. Challenges to the growth of engineering education research, such as funding and graduate student inclusion, are also discussed. In addition, we explore the emergence of teaching stream engineering faculty and problematize the role of research and scholarship in their career trajectories. Finally, we call for more strategic thinking to guide the evolution of engineering education research in Canada. We hope that, collectively, this editorial and the other four papers in this Special Theme will help to stimulate discussion about how we define and recognize excellence in the domain of engineering education research in Canada.
\end{abstract}

L. E. C.-A. Burke $(\bowtie)$

Ontario Institute for Studies in Education, University of Toronto, 252 Bloor St W., Toronto, ON M5S 1V6, Canada

e-mail: carolann.burke@utoronto.ca

\section{A. Chong}

Faculty of Applied Science and Engineering, Institute for Studies in Transdisciplinary Engineering Education and Practice, University of Toronto, Sandford Fleming B670, 35 St. George Street, Toronto, ON M5S 1A4, Canada

e-mail: alan.chong@utoronto.ca

\section{G. J. Evans}

Institute for Studies in Transdisciplinary Engineering Education and Practice, University of Toronto, 55 St George Street, Toronto, ON M5S OC9, Canada

e-mail: greg.evans@utoronto.ca

L. Romkey

Division of Engineering Science, Institute for Studies in Transdisciplinary Engineering Education and Practice, University of Toronto, Room 2110, 40 St. George Street, University of Toronto, Toronto, ON M5S2E4, USA

e-mail: lisa.romkey@utoronto.ca 
Résumé À bien des égards, la recherche en didactique de l'ingénierie au Canada est encore en train de s'établir comme discipline, même si on lui en demande déjà beaucoup. La diversité des cheminements de carrière des diplômés en ingénierie, la complexité accrue des défis mondiaux en ingénierie ainsi que les ramifications des possibilités technologiques, soulèvent des questions importantes sur les enjeux qui sont priorisés et sur les pratiques actuelles dans la formation en ingénierie. Cet article rassemble les questions soulevées au moyen d'un Thème spécial sur la recherche en formation des ingénieurs au Canada, et positionne la collection d'articles en fonction des défis et des possibilités auxquels est confrontée cette communauté de recherche canadienne en pleine maturation. Nous cherchons à concilier comment la recherche peut intégrer la profondeur théorique et méthodologique valorisée dans les sciences sociales, tout en honorant l'accent mis sur les pratiques pédagogiques efficaces qui sont devenues un important volet de recherche dans la formation en ingénierie. Les défis pour la croissance de la recherche en didactique de l'ingénierie, par exemple le financement et l'inclusion des étudiants diplômés, sont également abordés. De plus, nous explorons l'émergence de corps professoraux en ingénierie dont la principale - voire la seule fonction est l'enseignement, et nous problématisons le rôle de la recherche et des programmes de bourses dans leur trajectoire professionnelle. Enfin, nous demandons une réflexion plus stratégique pour guider l'évolution de la recherche en didactique de l'ingénierie au Canada. Nous espérons que, collectivement, cet éditorial et les quatre autres articles de ce thème spécial contribueront à stimuler la discussion sur la façon de définir et de reconnaître l'excellence dans le domaine de la recherche en formation des ingénieurs au Canada.

Keywords Engineering education · Research · Theory · Practice $\cdot$ Rigour $\cdot$ Excellence

\section{Introduction}

Engineering education research has only a brief formal history in Canada, even though Canadian engineering educators have been involved in the global community for a much longer period. This history began in earnest with the founding of the Canadian Design Engineering Network (CDEN) in 2000, which focused on bringing together engineering design educators to share ideas and teaching practices (Yellowley et al., 2001). In 2010, the CDEN was subsumed by the Canadian Engineering Education Association-Association Canadienne de L'Éducation en Génie (CEEA-ACEG), who broadened the mission to focus on enhancing 'the competence and relevance of graduates from Canadian Engineering schools through continuous improvement in engineering education and design education' (CEEA-ACEG, 2019). The CEEA-ACEG annual conference has become a formal site for sharing best practices and research in engineering education, with its proceedings constituting a catalogue of specifically Canadian work.

The papers comprising this Special Theme of the Canadian Journal of Science, Mathematics and Technology Education emerge from work shared at CEEA-ACEG conferences. This collection of papers bears the marks of a nascent discipline, and this editorial documents some of the philosophical and practical challenges and opportunities facing the growth and development of engineering education research in Canada. Like many other emerging disciplines, engineering education in Canada is still negotiating important questions such as what counts as high-quality research in the space. In this editorial, we foreground challenges that shape our current landscape as a domain located between the values of two distinct disciplines: engineering and education. Particularly, we explore the term excellence, so frequently used in academic realms to make declarations regarding the quality of teaching and research conducted by faculty members. We examine the tensions inherent in the either/or positioning of defining excellence as a measure of the theoretical and methodological depth of empirical studies as opposed to effective and impactful instructional practices. We acknowledge some of the fundamental barriers for young disciplines trying to establish a body of research that is recognized as being of high quality; these barriers include difficulties in communicating the value of this work to funders and those who evaluate the work of faculty 
members. Despite these challenges, we identify some promising trends that give us hope that engineering education research has a healthy future in Canada and we end by exploring possibilities for the way ahead.

\section{Engineering Education Research in North America and Beyond}

The American Society for Engineering Education (ASEE) provides a historical account of the formal organization of engineering education research in North America (ASEE, 2018a). They detail the emergence of this distinct area of scholarship since the formation of the Society for the Promotion of Engineering Education (SPEE) in 1893. The initial focus of the SPEE was to develop a form of engineering education that has a strong academic foundation, rooted in science and mathematics concepts, complementing the already well-established applied approaches to engineering education. The society was renamed the American Society for Engineering Education (ASEE) in 1946, incorporating the war-time emphasis on research and innovation. Currently, the ASEE has a global membership of over 12,000.

Complementing the work of the ASEE, the International Society for Engineering Pedagogy was founded in Austria in 1972 to scientifically link engineering and pedagogy. That organization has since developed a model engineering curriculum and confers the title of International Engineering Educator to various engineering education centres around the world that conform with their curriculum framework. Many countries and regions around the world have their own societies, associations, and programs devoted to engineering education; the International Federation of Engineering Education Societies, which recently celebrated its tenth anniversary, coordinates the efforts and activities of many of these organizations.

Alongside the rise in professional organizations drawing together engineering education researchers regionally, nationally, and internationally, there are several journals in place to encourage the sharing of scholarly research and teaching practices in the field. These include the Journal of Engineering Education (initially titled the Bulletin of the Society for the Promotion of Engineering Education; ASEE, 2018b), a product of the ASEE and often regarded as the top journal in engineering education. In 1993, the journal made a clear shift away from publishing accounts of teaching practice towards the publication of researchoriented works (ASEE, 2018b). This transition was supported by an increase in National Science Foundation (NSF) funding in the late 1980s, which was motivated by a desire to produce stronger engineering talent in the USA (National Academy of Engineering, 2004).

The complicated history of societies, associations, and journals seeking to embrace research-oriented approaches to engineering education, while remaining firmly connected to the identification and improvement of the signature pedagogies in the discipline, is reflected in the program of many engineering education conferences. This means that academics who wish to demonstrate the application of a new technology or pedagogy used in their university classrooms may be drawn into the same conference spaces as those who have introduced new program-level curriculum changes to support students, those who have conducted comprehensive reviews of literature on given areas of engineering education, or those conducting instructional interventions in the classroom. The complex mixture of theory and practice emphases in engineering education research is an ongoing challenge in defining the field and has become quite a conundrum for Canadian engineering education researchers.

\section{Engineering Education Research as a Developing Field in Canada}

In part because of the close ties with the more-established US engineering education research community and various international organizations, Canada has lagged behind in establishing societies, conferences, journals, and (most importantly) a clear set of parameters for the engineering education research field. Canadian academics have had the opportunity to easily engage with the ASEE and its associated journals 
and activities but a recurring call has been heard for Canadian engineering education to establish its own identity and research agenda, creating spaces to respond to Canada-specific concerns and interests.

Around the same time that CEEA-ACEG was established, the organization responsible for assessing undergraduate engineering programs, the Canadian Engineering Accreditation Board (CEAB), introduced an outcomes-based accreditation model. Rather than focusing engineering accreditation on monitoring the time spent on various courses, CEAB introduced a system of graduate attributes, emphasizing nontechnical engineering competencies such as teamwork, communication skills, professionalism, ethics and equity, and lifelong learning alongside the engineering knowledge base and technical competencies, such as problem analysis and design (Engineers Canada, 2018). This recent trend to more broadly define the scope of engineering education has run parallel to and, arguably, opened the door to new emphases in engineering education research in Canada (as reflected in this editorial and the articles that appear in this Special Theme).

Although Canadian engineering education now has its own national association (CEEA-ACEG), that organization has tended to use the proceedings of its conference series as the main outlet for Canadian engineering education research. Unlike its US counterpart, CEEA-ACEG has not yet established a research journal and this may be one of the factors contributing to the challenge in defining a Canadian perspective on what qualifies as high-quality research in the field.

Over the past decade, the CEEA-ACEG conference has grown significantly and its archives chart how engineering education research interests have evolved in the country over that period of time. While the number of papers presented may serve as an indicator of research activity, it is challenging to define research in a space where, as observed with the ASEE conference contributions, such a broad range of engineering education 'work' is being presented. Having some mechanism for resolving this ambiguity with regard to what forms of work count as good research would certainly be supportive of academics new to the field of engineering education, who wish to contribute to the body of research. Indeed, Brennan et al. (2018) conducted a systematic review of all of the papers presented at the conferences of CEEA-ACEG and its parent organizations from 2004 to 2017 to track the shift in the proportion of engineering practice to engineering research/theory papers over the years.

Brennan et al.'s (2018) paper speaks to the concept of rigour. Rigour is commonly discussed with regard to research in any emerging discipline, but it has become something of a preoccupation in engineering education research (Riley, 2017). Brennan et al. used an adaptation of the framework for rigour published by Streveler et al. (2007) in their summary of the work conducted by the National Science Foundation-funded project Conducting Rigorous Research in Engineering Education: Creating a Community of Practice. In Brennan et al.'s article, Canadian engineering education conference papers were classified into six overlapping subcategorizations of either theory- or practice-based research, where practice-based research was defined as focused on 'improving teaching structures and methods' (p. 3) and theory-based research was explained as being focused on 'understanding the learning process at a fundamental level' (p. 3). Brennan et al. concluded that, although there is a trend towards more rigorous papers, even in 2017, theorybased papers accounted for less than $30 \%$ of conference papers presented. The researchers went on to express concern about the growing antagonism seen outside of Canada between the two camps of academics in engineering education: the practitioners and the theoreticians. Their hope was that this trend would not extend into the Canadian context.

As authors of this editorial, our own discussions have led us to articulate a range of concerns with this system of classifying rigour in engineering education research and equating it with research quality; we will address three of those concerns in this paper. First, we examined the composition of the committee deriving the criteria for rigorous research in engineering education (Streveler et al., 2007) and were not surprised to see that alongside engineering educators and faculty developers were learning scientists as the key representatives from education research. This emphasis on the learning sciences as the central way of defining education research is, perhaps, part of the reason for the theory/practice division that seems to have become reinforced over the last decade in Canada. 
Placing so much emphasis on teaching and learning activities and processes negates a lot of the excellent research that examines the sociocultural influence of, and implications on, engineering education, as well as undervaluing many of the critical approaches to investigating engineering educational situations. We are concerned about rigour in research being defined by the domainspecific definitions of education research put forward by just one subfield in the vast body of education research.

This brings us to emphasize a second point; researchers on the Conducting Rigorous Research in Engineering Education project stated that their guidelines on rigour are aligned with the National Research Council's criteria for Scientific Research in Education (Streveler and Smith, 2006; Towne and Shavelson, 2002), but we acknowledge the subjectivity inherent in these criteria. As described so persuasively by Gee (2005), basing an evaluation of rigour on a framework that uses terminology such as 'significant questions', 'relevant theory', and 'explicit chain of reasoning' only highlights the contextual nature of these terms and how meaningless they can be outside of the frames of understanding endorsed by the domain within which they are being interpreted. Gee's assertions lead us to call for an examination of the theories to which we are currently committed in engineering education, naming them so that we can start challenging and dismantling the barriers that shut down opportunities to engage in important questions that influence Canadian engineering education.

Finally, we consider this distinction between practice- and theory-based research and suggest that it represents a false dichotomy. Highlighting the distinction, Brennan et al. (2018) cite the work of Felder and Hadgraft (2013), stating that 'many significant engineering education reforms have been the result of initiatives that were not based on rigorous research: e.g., the shift towards an 'engineering science' in the 1950's [sic], the emphasis on capstone design in the 1990's [sic]' (Brennan et al., p. 5). However, there is no reason why future reforms should not be research informed, and subject to ongoing research as the initiatives unfold; such an approach might challenge the critique of reform in engineering education being motivated by industrial or political interest. We suggest that there are no educational initiatives that are beyond the scope of research and that the most valuable research should have direct implications for practice. We will return to these strands of concern as we focus our attention on conditions that might limit or promote growth in engineering education research in Canada.

Graduate Studies in Engineering Education Research

Graduate student interest in engineering education research is on the rise in Canada. As of September 2019, the only $\mathrm{PhD}$ level engineering education program offering in Canada is the Collaborative Specialization in Engineering Education at the University of Toronto. Nevertheless, engineering graduate students are finding ways to pursue engineering education-related thesis research at other Canadian universities. The emergence of engineering education as a field for graduate research comes with new graduate student communities and new challenges as they try to find their place at the intersection of multiple disciplines. Seniuk Cicek et al. (2020), in this Special Theme, describe this uncertainty in their collaborative autoethnography on the lived experiences of engineering education graduate students in Canada. The four researchers, who gained their graduate degrees from four different universities across Canada, used identity-trajectory as a theoretical framework to inform their analysis, and identified several interesting themes that included a feeling of 'homelessness', concerns about the legitimacy of their work amongst engineers, and questions about possible career paths. This work highlights the importance of considering graduate students and new researchers in the growth of engineering education research in Canada. Seniuk Cicek et al. suggest the construction of institution-based communities of practice as mechanisms to support identity development, and development of the field more generally. 
Funding for Engineering Education Research

In the USA, a single agency (the National Science Foundation) funds research in the sciences and engineering, as well as research in education in those fields. This funding arrangement differs in Canada in that the federal agency funding education research is the Social Sciences and Humanities Research Council (SSHRC) and research in physical science disciplines is funded by the Natural Sciences and Engineering Research Council (NSERC). Thus, for a discipline like engineering education that sits at the intersection of these two research fields, proposed projects may not resonate well with the conventions or perceptions of research excellence of either funding agency. In addition, Canada lags behind many highly industrialized countries in terms of its designated investment in science, technology, engineering, and mathematics (STEM) education research. The USA, in contrast, has recently allocated approximately $\$ 100$ million annually, through the National Science Foundation, for research to specifically improve undergraduate STEM education (Engineers Canada, n.d.). At a time in Canadian history when the nature and role of post-secondary education are undergoing substantial transformation, there are few resources and little incentive for engineering education to keep up with the trends, much less innovate. It is now more important than ever before that the engineering education research community presents itself as a coherent body to lobby for supporting the kind of scholarship that will be invaluable to the country.

\section{Teaching-Focused Faculty Members}

The recent interest and growth of engineering education research in Canada can also be linked to the growth in teaching-focused faculty positions in engineering at Canadian universities. These positions range from teaching stream or lecturer posts that lead to continuing (or permanent) appointments, to instructor or sessional (temporary) contracts. Canadian universities are increasingly using criteria that are broader than simply having a background in a traditional engineering subdiscipline to recruit teaching-focused faculty. Some of these new teaching-focused positions revolve around instruction in technical knowledge that is well aligned with one or more of the engineering subdisciplines, such as instruction in mathematics, computer programing, data analytics, engineering design, or discipline-based laboratories. These faculty members can, to varying extents, find appropriate academic homes within existing departments. However, challenges still arise in terms of widely varying career expectations and understandings of how to assess contribution and impact due to the broad teaching agendas. Other transdisciplinary teaching-focused positions also exist in areas such as communication, leadership, business, entrepreneurship, sustainability, and multidisciplinary design. For these faculty members, there is an even greater potential for disconnection from the expectations, values, norms, and cultures of traditional engineering departments.

Promotion and review of faculty members in these teaching positions typically include expectations of teaching excellence and educational leadership. Underlying themes are pedagogical innovation, curricular reform, and contributions and impact through the scholarship of teaching and learning. On one hand, CEEA-ACEG conference records indicate that these themes are promoting increased interest and engagement in engineering education research. On the other hand, the housing of engineering education within faculties of engineering highlight the differences between engineering and engineering education research and can create tensions in terms of how engineering education scholarship contributions are understood, perceived, and valued by peers. While scholarship and research activity are not necessarily expected, it may become a differentiator at the more senior stages, or in consideration for awards or other recognitions of excellence. Moreover, engineering education research can support recognition of contribution and impact beyond the classroom through various avenues of knowledge mobilization. This external recognition in turn provides teaching-focused faculty a mechanism to help build the reputations of their departments and institutions. Thus, greater clarity and consistency is needed on how research excellence in engineering education is assessed and contributes to review, promotion, and career trajectories. 
The traditions inherent in the engineering discipline create a bias in the epistemologies and methodologies more likely to be accepted by engineering colleagues outside of the engineering education research community. Research emphasizing large data sets, quantitative survey data, and elaborate statistical analyses may convince engineering colleagues of the rigour of the research being conducted, but the nuances and subtleties of educational contexts often require qualitative approaches that may be criticized as representing small-scale collections of personal stories; the generalizability of such work is often questioned so is less likely to influence programs or policies within a given department. This tension between quantitative survey-based intervention studies and well-theorized qualitative studies with small data sets surfaced through the creation of this Special Theme. We received many submissions that charted interventions such as the use of some form of technology-mediation in classrooms. Many of these approaches have already been well theorized within the research literature of the education discipline but researchers in the field of engineering education often launched straight into their quantitative studies, with large data sets and astute employment of statistical analysis; the studies were not usually grounded in a theoretical context that justifies the selection of survey instruments and items or that connects the findings to what has already been demonstrated in other contexts. If for no other reason than to be more efficient in avoiding the duplication of effort and resources, it is important that engineering education research finds ways to value and validate approaches that connect the studies they conduct with scholarship in other educational settings. In the papers that constitute this Special Theme, we have challenged the authors to do just that: connect with existing literature, be explicit about the rationales for the methods used, and show how the work may be read as generative in other contexts of engineering education.

\section{Some Important Trends in Engineering Education Research}

The papers in this Special Theme showcase a few key trends we have observed in engineering education that are currently underrepresented in the body of research literature: (a) examining the role of experiential learning; (b) investigating the structure and integration of professional and transdisciplinary skills; and (c) describing the development of the field itself, as experienced by practitioners. These first two trends are reflective of efforts in undergraduate engineering (in part, through new accreditation requirements and government priorities) to focus on the development of skills and competencies that will be used in the students' future professional lives. The third trend is reflective of the growing interest in engineering education as a discipline in Canada and the emergence of opportunities for research and thesis-based graduate studies in the field. In this section, these three trends will be described in more detail. This will be followed by a short discussion of other trends in engineering education research that have not been included in this Special Theme.

\section{Experiential Learning}

Experiential learning has a long history in engineering programs, with initial internship-based initiatives forming in North America in the early 1900s. In the Canadian context, experiential learning is being seen more and more as a gateway to employability in the field, as well as vital for in-context skill and knowledge development. In Ontario, for example, the Premier's Highly Skilled Workforce Expert Panel (2016) recommended that all post-secondary programs require their students to engage in at least one workintegrated learning opportunity/experience before graduation. It also encouraged the expansion of experiential learning opportunities throughout all post-secondary curricula. Due to its historical roots as a vocational subject at the post-secondary level, engineering has an established record of supporting experiential learning, particularly with its practical experience requirements. For engineering students, co-op programs or internships have typically been the site of this type of learning. However, experiential learning opportunities and pathways now exist throughout the curriculum, with industry partnerships and community-engaged learning opportunities being integrated into corner and capstone design courses. 
Experiential learning is typically defined as 'learning by doing', but such a definition misses several important aspects likely to be essential to the process. Learning in a professional context does not happen simply by dropping a student into a real-world scenario. There are important pre-conditions, such as skill matching, student/work colleague personalities, and work culture, that heavily influence the educational value of the work-based experience; similarly, there are also important post-conditions, such as the need for students' informed and thoughtful reflection on their own learning. Research directed towards understanding how experiential learning works within engineering remains limited. As Liu et al. (2020) explain in this Special Theme, there have been many studies that examine, measure, and argue for the positive outcomes of internship experiences, but few that look into contextual and interpersonal factors that influence learning within the work-based placement. Liu et al. conducted a review of salient literature to explore how studies have described workplace affordances and engagement of students in work or industry environments; the authors have identified strategies for and barriers to student learning within experiential learning contexts that provide important insights into how we can scaffold the learning that takes place during these invaluable educational experiences.

\section{Transdisciplinary Competencies}

Engineering skills and competencies are often used to describe characteristics desired in engineering graduates. These terms communicate what graduates can do as well as who they are. As described above, the Canadian Engineering Accreditation Board (CEAB) describes these characteristics in terms of graduate attributes. Within engineering education, embracing these transdisciplinary attributes moves learning beyond the physical and cognitive to the individual and affective. Transdisciplinary attributes can thus be viewed as a synthesis of competencies and internal perspectives that individual engineers bring to their activities to amplify their technical knowledge and strengths.

Within this Special Theme, two papers explore the development of these transdisciplinary competencies in a Canadian engineering education context. Engineering leadership encompasses a whole set of skills and seeks to nurture an engineer's capacity for teamwork, lifelong learning, and communication. Given the breadth of leadership, it should come as no surprise that opportunities for engineering students to develop leadership skills occur in a huge variety of modes, employing different pedagogical models, purposes, and methods. In this Special Theme, Klassen and Donald (2020) perform an initial survey of leadership offerings in a subset of Canadian institutions, exploring the variety of pedagogies alongside the internal and external factors that shape them. Instruction in personal, interpersonal, and organizational leadership was evident across the six institutions. Via their survey, Klassen and Donald develop a framework to support institutions in analysing and building an effective leadership curriculum in the future.

In another discussion of transdisciplinary competencies in this Special Theme, Rottmann and Reeve (2020) discuss efforts to integrate ethics and equity into the engineering curriculum at the University of Toronto; they describe specific curriculum interventions designed to help bridge the divide between ethics and equity. In particular, the authors illustrate some of the challenges inherent to exploring ethical concerns by describing an episode of 'backlash' that occurred in their classroom during a discussion of an ethics and equity case study; Rottmann and Reeve analyse the incident using concepts from equity literature and provide instructors with strategies for moving forward in this critical work.

\section{Other Trends}

Canada needs to develop a stronger and more vibrant community of engineering education researchers if it is to inform and guide the many transitions expected over the coming decade. In addition to the research explored in this Special Theme, there are other key areas of focus that we note. As discussed earlier, the precursor to CEEA-ACEG was a group of educators focused on the pedagogies of engineering design; this remains an area of important focus for engineering education research. The design of processes and 
products in the service of societal and environmental needs is the professional focus of many engineering graduates, and understanding how to best prepare students with authentic design learning experiences is critical. Research on the teaching and learning practices associated with engineering communication, teamwork, creativity, and ethics is often associated with the engineering design curriculum.

We have also observed that discipline-based education research (DBER) in engineering is a common theme at engineering education conferences. DBER in engineering focuses on teaching and learning within specific subdisciplines of engineering. This has long been the case in the USA, with ASEE conferences including several specific divisions for discipline-specific educational research. A National Academy of Science report (Singer et al., 2012) provides an extensive synthesis of the available literature on DBER in undergraduate science and engineering, recommending adoption of evidence-based teaching practices to improve learning outcomes in STEM. Specifically, the committee reported that 'research-based instructional strategies are more effective than traditional lecture in improving conceptual knowledge and attitudes about learning' (p. 3). Sadly, they also conclude that undergraduate science and engineering education research findings are not yet impacting faculty pedagogy. The committee suggests that 'these efforts are more likely to succeed if they are consistent with research on motivating adult learners, include a deliberate focus on changing faculty conceptions about teaching and learning, recognize the cultural and organizational norms of the department and institution, and work to address those norms that pose barriers to change in teaching practice' (p. 3). These findings present compelling justification for engineering education to exist as an identifiable domain within faculties of engineering, while illustrating the acute challenge for researchers in the field to mobilize their research to influence activities and actions, even within their own faculty homes.

\section{Possibilities for the Future of Engineering Education Research in Canada}

It is an exciting time to work in engineering education research in Canada, particularly given the role of rapidly developing technologies, the diversity of pathways for engineering graduates, and the evolution of instructional spaces in undergraduate education. However, these challenges and opportunities necessitate new ways of thinking in engineering education. Engineering has always been at the forefront of educating university students about emerging technologies, and we now find ourselves working and teaching during a time of true transformation with the development and deployment of artificial intelligence, which has the potential to touch every discipline and subdiscipline of engineering. We need to consider how to best educate our students so that they can engage in the development and use of these technologies while considering the social and environmental impacts of technologies, and the ethical decision-making required to deploy transformative technologies in a responsible manner.

Engineering graduates pursue a diversity of post-graduate pathways; while some work within private sector industries, many are pursuing entrepreneurship, working for start-ups, finding engineering opportunities in newer industries such as quantitative finance and social innovation, and pursuing opportunities outside of engineering entirely. This range of outcomes, coupled with the aforementioned rapidly developing technologies, highlight a need to prepare students with a diverse set of skills, and encourage a sense of lifelong learning that extends beyond the four years of an engineering degree. This is a critical time to reinforce the need for research-informed innovation in teaching and learning. As we consider the issues raised in this editorial, we end by highlighting some possibilities for the field of Canadian engineering education research.

In educational research, terms such as rigour and excellence can be loaded, often masking the theories and assumptions that are validated in the field. Making these values more explicit in the context of Canadian engineering education research can help new scholars see their potential for contributing to the field, as well as open spaces for certain norms of inclusion and exclusion to be challenged in support of progress in the discipline. More specifically, we feel that efforts to discern research quality and articulate excellence should not become entrenched within exclusionary disciplinary barriers, based on inherited or borrowed norms for 
rigour that may have been insufficiently examined. A clearer and more inclusive understanding of engineering education research quality and excellence will help to guide the review, promotion, and career trajectories of faculty.

We have also discussed concerns about a growing divide between adherents to the priorities of instructional practice versus theory-informed empirical studies in Canadian engineering education research. Tension can be created if the engineering departments and the engineering education research community value different aspects of scholarship. Thus, mechanisms to acknowledge and bridge this divide are needed. In particular, understanding of and appreciation for the nature of engineering education research need to grow within engineering programs, and teaching-focused faculty need to be supported to grow their scholarship across a range of research approaches.

As a result of these considerations, we propose that a central step in progressing this discussion might be made by conducting research into the current ways in which engineering education research is conceived in the field in Canada. We consider the potential of the kind of study conducted by Kaupp et al. (2015) who carried out a modified Delphi study, surveying the attitudes of Canadian engineering instructors towards teaching and learning. We propose that this kind of study might be a fruitful starting point for discussions about engineering education research in Canada. A Delphi study invites key participants in the field to contribute their perspectives on a given topic, with a view to gathering a group response without direct confrontation or debate between contributors (Brown, 1968). This study could complement the research conducted by Kaupp et al. by extending the focus to identify priorities for an engineering education research agenda. Making the collective perspectives explicit would support opportunities for engagement and discussion that will help to shape the field. In addition, the outcomes of such a study would provide a focal point around which a given faculty group might start conversations about their own directions for engineering education research. We see this kind of research as having great potential as a springboard for proposing a Canadian journal of research in engineering education.

Another possibility for the field of engineering education research is the rise of the STEM construct in Canadian K-12 education. Previous issues of this journal have illustrated some of the challenges and opportunities that the STEM acronym has presented in Canada and beyond; we see a lot of potential for developing STEM-based research collaborations that support engineering practitioners as they grapple with the broad and varying field of education research. We also see scope for engineers to support research that seeks to incorporate the engineering component into integrated STEM approaches, alongside science, technology, and mathematics disciplines that are well established in K-12 education in Canada. This reciprocal exchange of expertise between academics in engineering education and science, mathematics, and technology education specialists can support growth in both fields.

Finally, we suggest that individuals embarking on an engineering education research career in Canada would also find support by developing research partnerships with researchers in adult and higher education. Such collaborations could provide a stronger baseline for discipline-based education research, particularly as it concerns undergraduate engineering contexts. Ultimately, these collaborations with education researchers may provide insights into ways of interpreting the conventions and expectations of funding agencies in the social sciences, such as SSHRC.

Above we have identified some of the strategic ways of thinking that merit closer investigation if engineering education research is going to be effective in responding to contemporary needs. We have suggested some distinct avenues for growth and development in the field, but we have also identified potential areas of impact the field can have in support of the education discipline. Canadian engineering education research is at a turning point and we hope that this Special Theme can act as a stimulus for action in the field.

Acknowledgements We would like to acknowledge the authors who engaged in this process; whether their papers are included in the Special Theme, or if they were part of the process along the way, we are very grateful for their engagement. We would also like to thank the group of reviewers who volunteered their time to provide invaluable feedback on the shortlisted papers. 


\section{References}

ASEE (2018a). About [official website of national organization]. Retrieved from https://www.asee.org/about-us/theorganization. Accessed 16 Dec 2019.

ASEE (2018b). Publications [official website of national organization]. Retrieved from https://www.asee.org/papers-andpublications/publications/jee/history-of-jee. Accessed 16 Dec 2019.

Brennan R, Hugo, R., Johnston, K., Nelson, N., Paul, R., \& Sullivan, M. (2018). A Systematic Review of Canadian Engineering Education Research 2004-2017. Proceedings of the Canadian Engineering Education Association (CEEA-ACEG). https://doi.org/10.24908/pceea.v0i0.13079

Brown, B. B. (1968). Delphi process: A methodology used for the elicitation of opinions of experts (No. RAND-P-3925). Santa Monica: The RAND Corporation.

CEEA-ACEG (2019). About [official website of national organization]. Retrieved from https://ceea.ca/en/about/. Accessed 16 Dec 2019.

Engineers Canada (n.d.). STEM education research funding. Retrieved from https://engineerscanada. $\mathrm{ca} /$ sites/default/files/public-policy/STEM-Education-Research-Funding-EN.pdf. Accessed 16 Dec 2019.

Engineers Canada (2018). 2018 Accreditation criteria and procedures. Retrieved from https://engineerscanada. $\mathrm{ca} /$ sites/default/files/accreditation/Accreditation-criteria-procedures-2018.pdf

Felder, R. M., \& Hadgraft, R. G. (2013). Educational practice and educational research in engineering: partners, antagonists, or ships passing in the night. Journal of Engineering Education, 102(3), 339-345.

Gee, J. (2005). It's theories all the way down: A response to scientific research in education. Teachers College Record, 107(1), $10-18$.

Kaupp, J., Doré, S., Young, S., Frank, B., Ostafichuk, P., McCahan, S., \& Nesbit, S. (2015). The Canadian Engineering Education Association Research Collaboration (CEEA-RC): Annual Survey of Canadian Engineering Instructors. Proceedings of the 2015 Canadian Engineering Education Association (CEEA) Conference. Retrieved from https://ojs.library.queensu.ca/index.php/PCEEA/article/view/5814. Accessed 16 December 2019.

Klassen, M., \& Donald, J. (2020). Developing a taxonomy to compare engineering leadership curriculum across Canadian universities. Canadian Journal of Science, Mathematics and Technology Education, 20(1). https://doi.org/10.1007 /s42330-019-00072-8

Liu, Q., Reeve, D., Rottmann, C., \& Moore, E. (2020). Examining workplace affordance and student engagement in engineering co-op and internship literature. Canadian Journal of Science, Mathematics and Technology Education, 20(1). https://doi.org/10.1007/s42330-019-00074-6

National Academy of Engineering. (2004). The Engineer of 2020: Visions of Engineering in the New Century. Washington: The National Academies Press. Retrieved from. https://doi.org/10.17226/10999

Premier's Highly Skilled Workforce Expert Panel. (2016). Building the workforce of tomorrow: A shared responsibility. Toronto: Queen's Printer for Ontario. Retrieved from https://files.ontario.ca/hsw_rev_engaoda_webfinal_july6.pdf. Accessed 16 Dec 2019.

Riley, D. (2017). Rigor/Us: Building boundaries and disciplining diversity with standards of merit. Engineering Studies, 9(3), 249-265.

Rottmann, C., \& Reeve, D. (2020). Equity as rebar: Bridging the micro/macro divide in engineering ethics education. Canadian Journal of Science, Mathematics and Technology Education, 20(1). https://doi.org/10.1007/s42330-019-00073-7

Seniuk Cicek, J., Paul, R. M., Sheridan, P., \& Kuley, L. (2020). Canadian Journal of Science, Mathematics and Technology Education, 20(1).

Singer, S. R., Nielsen, N. R., \& Schweingruber, H. A. (Eds.) (2012). Discipline-based education research: Understanding and improving learning in undergraduate science and engineering. Washington: National Academies Press.

Streveler, R. A., Borrego, M., \& Smith, K. A. (2007). Moving from the 'scholarship of teaching and learning' to 'educational research': An example from engineering. In D. R. Robertson (Ed.), To Improve the Academy, 25 (139-149). Bolton: Anker.

Streveler, R. A., \& Smith, K. A. (2006). Conducting rigorous research in engineering education. Journal of Research in Education, 95(2), 103-105.

Towne, L., \& Shavelson, R. J. (2002). Scientific research in education. Washington: National Research Council.

Yellowley, I., Venter, R. D., \& Salustri, F. A. (2001). The Canadian design engineering network (CDEN/RCCI): sharing engineering design educational tools within thirty three schools of engineering in Canada. In Proceedings of the 8th World Conference on Continuing Engineering Education. Retrieved from https://deseng.ryerson.ca/dokuwiki/_ media/info:nsf01.pdf. Accessed 16 Dec 2019.

Publisher's Note Springer Nature remains neutral with regard to jurisdictional claims in published maps and institutional affiliations. 